\title{
DO RECONHECIMENTO JURÍDICO DAS UNIÕES POLIAFETIVAS COMO ENTIDADE FAMILIAR
}

\author{
Valéria Silva Galdino Cardin* \\ Carlos Alexandre Moraes**
}

SUMÁRIO: Introdução 2 Do conceito de poliamor; 3 Da evolução do Direito de família; 4 Estruturas e funções das famílias contemporâneas; 5 Do princípio da liberdade e do pluralismo familiar; 6 Da não intervenção do Estado nas relações particulares; 7 Do reconbecimento das uniões poliafetivas; 8 Conclusão; Referências.

RESUMO: Os relacionamentos poliafetivos estão pautados, sobretudo, nos vínculos afetivos, os quais são criados de uma forma não-monogamica, fugindo da norma padrão que a sociedade impõe como modelo familiar. Dessa maneira, o presente trabalho teve como finalidade analisar, pelo método teórico, o reconhecimento jurídico das uniões poliafetivas como entidade familiar. Para tanto, demonstrouse o conceito da poliafetividade, a evolução histórica do direito de família ao qual conduziu a sociedade ao novo modelo familiar. Da mesma forma, examinam-se os princípios norteadores do direito de família, que demonstram que as unióes poliafetivas podem ter seu status familiar reconhecidos por meio do conceito da pluralidade familiar, bem como do direito a não intervenção do Estado nas relações particulares.

PALAVRAS-CHAVE: Pluralidade familiar; Poliafetividade; União estável.

\section{JURIDICAL ACKNOWLEDGEMENT OF POLY-AFFECTIVE UNIONS AS A FAMILY UNIT}

ABSTRACT: Poly-affective relationships are mainly based on affective bonds formed non-monogamically and beyond standard norms which society conceives as the family rule. Current research analyzes theoretically the juridical acknowledgement of poly-affective unions as family unions. The concept of poly-affectivity and its

\footnotetext{
Pós-doutora em Direito, pela Universidade de Lisboa; Doutora e mestre em Direito das Relações Sociais, pela Pontifícia Universidade Católica de São Paulo; Docente no Programa de Pós-graduação em Ciências Jurídicas e do Curso de Direito do Centro Universitário de Maringá (UniCesumar), Docente da Universidade Estadual de Maringá e; Pesquisadora no Instituto Cesumar de Ciência, Tecnologia e Inovação ICETI; Advogada no Paraná, Brasil

${ }^{* *}$ Doutor em Direito pela Faculdade de Direito de São Paulo; Doutor em Ciências da Educação pela UPAP, Mestre em Direito, pelo Centro Universitário de Maringá (UniCesumar); Pós-doutorando em Direito pelo Centro Universitário de Maringá (UniCesumar), Brasil.
} 
historical evolution in family law and the reason why society was conducted to the new family model are demonstrated. The main principles in family law are examined where poly-affective unions are shown to have the family status acknowledged by family pluralism, coupled to the right of non-intervention by the State in private relationships.

KEY WORDS: Family pluralism; Poly-affectivity; Stable union.

\section{DEL RECONOCIMIENTO JURÍDICO DE LAS UNIONES POLI AFECTIVAS COMO ENTIDAD FAMILIAR}

RESUMEN: Los relacionamientos poli afectivos están de acuerdo, más bien, en los vínculos afectivos, los cuales son creados de una forma no-monógama, huyendo de la norma patrón que la sociedad impone como modelo familiar. De esa manera, en el presente estudio se tuvo como finalidad analizar, por el método teórico, el reconocimiento jurídico de las uniones poli afectivas como entidad familiar. Para eso, se demostró el concepto de la poli afectividad, la evolución histórica del derecho de familia al cual condujo la sociedad al nuevo modelo familiar. De igual manera, se examina los principios orientadores del derecho de familia, que demuestran que las uniones poli afectivas pueden tener su status familiar reconocidos por intermedio del concepto de la pluralidad familiar, así como del derecho a no intervención del Estado en las relaciones particulares.

PALABRAS CLAVE: Pluralidad Familiar; Poli afectividad; Unión Estable.

\section{INTRODUÇÃO}

Ao longo dos anos, a família brasileira foi regida por dogmas cristãos e costumes conservadores que adotaram o modelo patriarcal monogâmico heterogêneo. Todavia, essa realidade foi modificada com o advento da atual Constituição Federal, que passou a reconhecer outras formas de entidade familiar como, por exemplo, as uniões estáveis e a família monoparental.

O pluralismo das entidades familiares ocasionou mudanças na própria estrutura da sociedade, rompendo com os preceitos obsoletos que impediam os avanços no direito de família e fortalecendo, assim, a autonomia dos indivíduos nas relações privadas.

Nessa perspectiva, os arranjos afetivos têm demonstrado ao longo do 
tempo uma força estrutural distinta e por essa razão vem superando o preconceito enraizado que ainda vigora no seio da sociedade brasileira. A família poliafetiva é a mostra evidente desta evolução, sendo fundamental a discussão acerca do tema, uma vez que esses núcleos familiares precisam da devida proteção estatal, para ter seus direitos garantidos de forma plena.

Mas será que as relações poliamorosas são capazes de dar origem a um núcleo familiar, que seja merecedor de tutela jurídica?

$\mathrm{O}$ que consubstancia a entidade familiar? Seria o afeto, ou o dogma da monogamia que dissimula valores principiológicos no âmbito jurídico?

Para a realização da presente pesquisa, foi utilizado o método teórico, que consiste na pesquisa de obras, artigos de periódicos, e documentos eletrônicos que tratam do tema. Foi utilizado também o método de procedimento histórico, ao tratar, de forma sútil a evolução da família dentro da sociedade brasileira.

\section{DO CONCEITO DE POLIAMOR E POLIAFETIVIDADE}

Como a própria nomenclatura diz, poliamor significa a possibilidade de amar, sentir atração sexual e relacionar-se com mais de uma pessoa concomitantemente. A poliafetividade faz parte dessa variedade múltipla de inter-relações que compõe a sociedade contemporânea, e expressa de forma distinta que o sentimento é livre e pode ser manifestado de diversas maneiras.

O que não se confunde com nenhum tipo de promiscuidade, pois não se trata de procurar incessantemente por diversas experiências sexuais desvirtuadas, mas, sim, de manter total honestidade no seio das relações, sendo que todas as pessoas envolvidas estão a par da situação e se sentem confortáveis com ela.

Rompe-se com ideia do amor fundado em exclusividade e abre espaço para formas variadas de relacionamento que não são as tradicionais. Além de descontruir o conceito universal, de que o casal monogâmico seja a única estrutura válida de relacionamento humano.

A concepção de poligamia está comumente associada ao casamento de um homem com várias mulheres (poliginia), em oposição à poliandria (01 mulher casada com vários homens). Por essa razão, a palavra poligamia suscita reações contra a subjulgação de um sexo por outro. No entanto, o poliamor pressupõe uma 
igualdade de direitos, não só entre os sexos, mas entre todas as pessoas envolvidas. ${ }^{03}$

Ainda que alvo do repúdio social, os vínculos afetivos concomitantes nunca deixaram de existir em larga escala na sociedade ${ }^{04}$. Nesse sentindo, a definição de traição é baseada na ideia de que alguém falhou com o que foi prometido, iludindo o outro nos moldes do artigo 1.566, inciso I do Código Civil. No poliamor é diferente, não há traição, uma vez que as pessoas que se relacionam não escondem que amam outras. O relacionamento torna-se verdadeiro e, desde que todas as partes envolvidas estejam confortáveis com a situação, não há nada que possa impedi-las de se envolverem.

Há duas classificações no poliamor, sendo essas, o relacionamento aberto e o fechado. No primeiro, as pessoas entram e saem adeptos livremente, já na segunda os envolvidos moram juntos, formando uma única entidade familiar.

Para Regina Navarro Lins, o poliamor é uma relação interpessoal que ocorre quando múltiplos parceiros se envolvem simultaneamente de forma responsável, com intimidade profunda e, porventura, duradoura. ${ }^{05}$

No Brasil, o primeiro registro de união poliafetiva ocorreu no ano de 2012, na cidade de Tupã/SP, entre um homem e duas mulheres. O trisal já vivia juntos na mesma casa há três anos e oficializaram a união por meio de uma escritura pública, no cartório da cidade. ${ }^{06}$

O segundo caso relatado foi a união de três mulheres, na cidade do Rio de Janeiro, no ano de 2015, oportunidade em que o registro foi acompanhado por testamentos patrimoniais e vitais. ${ }^{07}$

Os declarantes, diante da lacuna legal do reconhecimento desse modelo de união afetiva múltipla e simultânea, por meio dos instrumentos hábeis, buscaram garantir seus direitos e deveres, pretendendo vê-los reconhecidos e respeitados social, econômica e juridicamente, tendo por base os princípios constitucionais da liberdade e do pluralismo familiar.

${ }^{03}$ VITERBO, Luís Miguel; POLY, Lara; CARDOSO, Daniel. Poliamor? O que é? Issuu, 2010. Disponível em: $<$ https://issuu.com/poliamor/docs/flyers_polyportugal > . Acesso em: 31 jul. 2018.

${ }^{04}$ DIAS, Maria Berenice. Poliafetividade, alguém dúvida que existe? Disponível em: <https://bit.ly/2JfxCp1 > . Acesso em: 26 jul. 2018

${ }^{05}$ LINS, Regina Navarro. A cama na varanda: arejando nossas ideias a respeito do amor e sexo: novas tendências. Rio de Janeiro: BestSeller, 2007, p. 327.

${ }^{06}$ UNIÃO Estável entre três pessoas é oficializada no cartório de Tupã, SP. G1/Globo comunicações, 2012. Disponível em <http://g1.globo.com/sp/bauru-marilia/noticia/2012/08/uniao-estavel-entre-tres-pessoas-eoficializada-em-cartorio-de-tupa-sp.html > . Acesso em: 27 jul. 2018.

${ }^{07}$ PIVA, Juliana Dal. Rio registra primeira união estável entre três mulheres. Jornal Folha de São Paulo, 2015. Disponível em: <https:/brasil.estadao.com.br/noticias/rio-de-janeiro,rio-registra-primeira-uniao-estavelentre-3-mulheres,1781538> . Acesso em: 27 jul. 2018. 
Todavia, recentemente o Conselho Nacional de Justiça julgou acerca da legalidade dessas uniões. O debate teve início em 04 de abril de 2016, quando a Associação de Direito das Famílias e das Sucessões (ADFAS) entrou com um pedido para que a entidade impeça o registro de uniões entre mais de duas pessoas. Nove dias depois, a ministra Nancy Andrighi concedeu uma liminar recomendando aos tabeliães de notas do país que aguardassem o julgamento do caso. ${ }^{08}$

E no dia 27 de julho de 2018, o conselho decidiu que os cartórios estão proibidos de emitir qualquer documento que reconheça as uniões poliafetivas. Os ministros entenderam que o reconhecimento da união estável dessas relações contradiz com a normatização das relações familiares previstas na Carta Magna e no Código Civil e, por essa razão, os cartórios têm de estar em plena consonância com o sistema jurídico. ${ }^{09}$

Nesse sentido, Angélica Ferreira Rosa e José Sebastião de Oliveira esclarecem que

[...] a regulamentação pelo $\mathrm{CNJ}$ tem que garantir os direitos dessas pessoas que estão envolvidas nessas relações e de todas aquelas que mesmo não tendo registrado sua situação fática se inserem nesses casos, afinal, as relações humanas não são mais baseadas unicamente na hierarquia de um sistema tradicional e biologicista. ${ }^{10}$

Por outro lado, Maria Berenice Dias entende que o rol familiar descrito na atual Constituição Federal não é taxativo, sendo possível inferir que a lei protege não só a família oriunda do matrimônio, mas também a informal, a homoafetivas, a anaparental, a pluriparental, a paralela e a poliamorista, desde que haja a presença da afetividade, do companheirismo e da ajuda mútua entre os membros. ${ }^{11}$

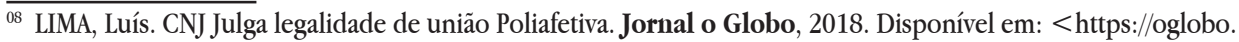
globo.com/sociedade/cnj-julga-legalidade-de-uniao-poliafetiva-22682855> . Acesso em: 27 jul. 2018

09 TEIXEIRA, Matheus. Relações a três. Disponível em: < https://www.jota.info/justica/cnj-proibe-que-cartoriosunioes-poliafetivas-26062018>. Acesso em: 27 jul. 2018

${ }^{10}$ ROSA,Angelica Ferreira; DE OLIVEIRA, JoséSebastião. As relações poliafetivas são permitidas no direito de família brasileiro? Revista Argumenta, Jacarezinho, n. 26, p. 197-218, jan./jun. 2017. Disponível em: < https://search. proquest.com/openview/131b2dafa5c323ec23e68eee278bed10/1?pq-origsite $=$ gscholar \&cbl $=2031966>$. Acesso em: 26 nov. 2018.

${ }^{11}$ DIAS, Maria Berenice. Manual de Direito das Famílias. 5. ed. São Paulo: Revistas dos Tribunais, 2013, p. 44-54.
} 


\section{DA EVOLUÇÃO DO DIREITO DE FAMÍLIA}

A antiga família romana formava-se em razão da religião doméstica do culto familiar aos antepassados, que era restrito aos seus membros. Os rituais eram praticados pelo patriarca chefe da família, que possuía poderes ilimitados, o pater famílias. Os laços de filiação na família se perpetuavam por meio do culto doméstico, independentemente de afeto. ${ }^{12}$

Já com as influências do cristianismo, a família passou a se manifestar de forma ideológica, transmitindo a impressão de respeitabilidade, espelhado na sagrada família, e ainda continuava hierarquizada pelo patriarca, como foi visto na família colonial, perdurando até o século XIX.

A família brasileira formou-se como unidade de produção e consumo, era fundada em um núcleo religioso acima de tudo, mas também patrimonial e político. A partir do século XIX, o Estado começou a interferir na família, impondo regras impositivas e engessando o modelo de composição, que era legitimado apenas pelo casamento. $^{13}$

Com o advento da Constituição Federal de 1988, o conceito de família sofreu relevante mudança e trouxe alguns marcos significantes para a concretização do atual quadro social brasileiro. Legitimaram-se situações sociais que antes não eram concebidas pelo conservadorismo tradicional que a Igreja Católica manteve durante anos.

Rastreando os fatos da vida, o legislador viu a necessidade de conhecer a existência de outras entidades familiares, além das constituídas pelo casamento. Assim, a união estável ganhou reconhecimento, como também, a comunidade formada por qualquer um dos pais com seus descendentes, que passou a ser reconhecida como família monoparental. Mas não somente nesse limite se manteve o conceito de família, pois o rol apresentado pela Constituição é meramente exemplificativo. ${ }^{14}$

Dentro desse espectro mais amplo, não seria possível excluir do âmbito do direito das famílias os relacionamentos homoafetivos, que mantém entre si ligações puramente afetuosas e, apesar das manifestações preconceituosas contrárias a essas uniões, não é mais possível deixar de garantir a tutela jurídica dessas famílias. Em

\footnotetext{
$\overline{12}$ CARVALHO, Dimas Messias. Direito das famílias. 5. ed. São Paulo: Saraiva, 2017, p. 43.

${ }^{13}$ ROSA, Conrado Paulino da. iFamily: um novo conceito de família? São Paulo: Saraiva, 2013.

${ }^{14}$ DIAS, Maria Berenice. Manual de Direito das Famílias. 9. ed. São Paulo: Revistas dos Tribunais, 2013, p. 40.
} 
decorrência dos avanços da jurisprudência, o Supremo Tribunal Federal se viu compelido a declarar, com caráter vinculante e eficácia erga omnes, que as uniões de casais do mesmo sexo são também uma entidade familiar. ${ }^{15}$

No sentido estrito atual, o novo modelo de família funda-se sobre os pilares da personificação, da efetividade, da pluralidade e do eudemonismo, implicando nova roupagem axiológica ao direito de família. ${ }^{16}$

Grande parte desse pluralismo, que define a família atual, decorreu da evolução social, em que as mulheres conquistaram alguns direitos que antes eram inconcebíveis, como por exemplo: a concessão dos direitos políticos, a emancipação profissional e econômica feminina e, até mesmo, o status de isonomia conjugal, o qual igualou os direitos e deveres da mulher e do homem no casamento, concebendo, então, outro papel da mulher dentro do seio familiar, mais independente e autônomo.

Conrado Paulino da Rosa acrescenta um tipo de família, a online ou iFamily, que advém da sociedade virtual que vivenciamos na atualidade, onde os contratos, conversas e negócios são realizados cotidianamente por intermédio da Grande Rede. $\mathrm{O}$ autor cita que a sociedade vive profunda mutação antropológica e sociológica decorrentes dos constantes avanços da tecnologia, em especial na comunicação. ${ }^{17}$

Portanto, o conceito moderno de família é a comunidade formada pelo afeto de seus membros, que busca a felicidade de forma particular e individual, o que faz com que seus integrantes passem por um processo de emancipação.

O elemento constitutivo dessa instituição social é o afeto, ao qual se constrói por meio de relações de sentimentos entre seus integrantes, sendo que as pessoas que estão envolvidas buscam a realização pessoal, e por essa razão a proteção jurídica da família se desloca da instituição para o sujeito, de maneira individualizada, assegurando, portanto, a almejada privacidade que os indivíduos buscam habitualmente. Para tanto a própria Constituição Federal, prevê em seu art. 226, $\S 8^{\circ}, 1^{\circ}$ parte, que o Estado tem o dever de prestar especial proteção e assegurar à família, bem como de prestar assistência, na pessoa de cada um dos seus integrantes, de forma individual. ${ }^{18}$

\footnotetext{
${ }_{15}$ BRASIL, Supremo Tribunal Federal. Ação Direita de Inconstitucionalidade 4277, Rel. Min. Ayres Brito, j. 2011.

${ }^{16}$ DIAS, Maria Berenice. Manual de Direito das Famílias. 3. ed. São Paulo: Revistas dos Tribunais, 2006, p. 39.

${ }^{17}$ ROSA, Conrado Paulino da. Op. cit., 2013.

${ }^{18}$ Art. 226. A família, base da sociedade, tem especial proteção do Estado. $\S 8^{\circ} \mathrm{O}$ Estado assegurará a assistência à família na pessoa de cada um dos que a integram, criando mecanismos para coibir a violência no âmbito de suas relações.
} 
Dessa forma, é evidente que, ao longo do tempo, houve mudanças profundas quando o Estado passou a tutelar de forma constitucional os direitos acerca da família, definindo e ampliando modelos que antes não eram concebidos na sociedade, tão pouco na legislação e na jurisprudência.

\section{ESTRUTURAS E FUNÇÕES DAS FAMÍLIAS CONTEMPORÂNEAS}

Conforme elucidado, o modelo adotado pelo constituinte pressupõe a existência de uma pluralidade de estruturas familiares, sendo que nenhuma delas possui papel hierárquico frente às outras ${ }^{19}$. Cada tipo de família representa um núcleo diferente, e todas manifestam igual potencial de desenvolver as suas funções intrínsecas, tais como cuidado, afetividade, respeito, educação das crianças, solidariedade e assistência mútua entre os seus membros.

Embora ainda exista forte resistência dos defensores da família tradicional monogâmica e heterogênea, a pluralidade das entidades familiares mostra-se cada vez mais latente no seio da sociedade.

A família, da forma como vem se transformando paulatinamente, impossibilita identificá-la como um modelo único. Ao contrário, ela se manifesta como um agrupamento de trajetórias individuais, que expressam os mais diversificados espaços domiciliares.

As estruturas familiares da contemporaneidade podem variar entre uniões consensuais de parceiros separados ou divorciados; uniões de pessoas do mesmo sexo; uniões de pessoas com filhos de outros casamentos; mães ou pais sozinhos com seus filhos; avós com os netos; e uma infinidade de formas a ser definida, colocando-nos diante de uma nova família, diferenciada do clássico modelo de família nuclear. ${ }^{20}$

Cada vez mais são identificadas famílias que se destoam das estruturas tradicionais, cujos papéis eram rigidamente definidos com base nas regras patriarcais e machistas da época. No entanto, na atualidade o que se destaca é precisamente o contrário disto, como já mencionado, as famílias contemporâneas são estruturadas por múltiplas formas, e aquilo que anteriormente era regra, já não é mais. Exemplo

\footnotetext{
${ }_{19}$ ROUDINESCO, Elisabeth. A família em desordem. Rio de Janeiro: Zahar, 2003.

${ }^{20}$ OLIVIEIRA, NHD. Recomeçar: família, filhos e desafios. São Paulo: UNESP; Cultura Acadêmica, 2009. Disponível em: < https://bit.ly/2nwIKDT> Acesso em: 02 jul. de 2018.
} 
disto são as mulheres solteiras, que dominam o papel que antes era dito masculino, trabalhando fora de casa, criando seus filhos de forma autônoma e rompendo com a ideia de que necessariamente é preciso existir uma figura masculina para acompanhá-la ou para formar um núcleo familiar.

Na redação dada pela Constituição Federal de 1988, o legislador, de forma democrática, estabeleceu um conceito mais abrangente do que é família no art. 226, $\S 4^{\circ}$, o qual não especifica quem a forma, mas fundamenta a família sob o viés dos laços afetivos. ${ }^{21}$

Nesse contexto, Dimas Messias de Carvalho ${ }^{22}$ apresenta quatro elementos para caracterizar as famílias simultâneas, e que podem ser usadas como parâmetro comparativo para dar legitimidade às composições das famílias poliafetivas, e afastando da proteção estatal dos relacionamentos eventuais e clandestinos. O primeiro é a boa-fé objetiva, que ocorre quando um dos parceiros não tem conhecimento da existência de outra família, havendo a lealdade. O segundo elemento é a afetividade, que é componente agregador da família e que confere comunhão de vidas nos relacionamentos. O terceiro é a estabilidade, exigindo que o vínculo seja duradouro, contínuo e estável evitando relações passageiras, eventuais, sem compromisso de constituir uma família. Por fim, o quarto elemento é a ostensibilidade, vendando-se a clandestinidade. É necessário que o meio social reconheça aquele relacionamento como um núcleo familiar. ${ }^{23}$

Para Dimas Daniel de Carvalho ${ }^{24}$, as estruturas familiares contemporâneas vêm ultrapassando os preconceitos e os dogmas conceituais concernentes às relações afetivas, e na omissão do legislativo, cabe ao juiz analisar cada caso concreto, e mediante o dever de proteção conferir as uniões estáveis, se presentes seus elementos essenciais, sua efetiva proteção e produção de efeitos, em razão de não existir nenhuma norma que equipare a bigamia ou proíba o conhecimento dos seus efeitos ao mundo jurídico.

Diante desse entendimento, nota-se o quão indesejada é a intercessão indevida na família, que deve sempre privilegiar a independência privada de seus membros em prol do princípio da liberdade e da igualdade. A liberdade de escolha e o planejamento familiar fazem parte das múltiplas formas democráticas de se formar

\footnotetext{
${ }^{21}$ MOITINHO, Rodrigo. et al. Poliamorismo e o reconhecimento das relaçóes poliafetivas como núcleo familiar. 2018. Disponível em: < https://bit.ly/2MG6Ffr> . Acesso em: 02 jul. de 2018.

${ }^{23}$ CARVALHO, Dimas Messias. Direito das famílias. 5. ed. 2 São Paulo: Saraiva, 2017, p. 67.

${ }^{24}$ Ibidem, p. 66-67.
} 
uma família e são regidas por institutos legais que determinam suas condições mínimas.

Dessa maneira a lei pode estabelecer a medida necessária para regulamentar essas relações, sem que haja qualquer interferência arbitrária do Estado, ou de qualquer outro meio que queira interferir na liberdade das pessoas em se relacionarem entre si.

\section{DO PRINCÍPIO DA LIBERDADE E DO PLURALISMO FAMILIAR}

À medida que novos núcleos familiares começaram a surgir e foram sendo reconhecidos pela Constituição Federal, ficou estabelecido que a família é a base da sociedade e que, por essa razão, merece especial proteção do Estado. O que mais tarde também foi consagrado pelo Código Civil em 2002. Fica evidente que a intenção do legislador é de tornar a família uma instituição democrática, regida pelo princípio da liberdade e do pluralismo familiar.

Em decorrência da democratização pela qual a família passou, focada atualmente na preservação da dignidade da pessoa humana, o sentimento de afeto que une as pessoas prevaleceu em relação as regras tradicionais dessas uniões. Com o afeto na formação da personalidade humana e na constituição das relações familiares, a interferência do poder público diminuiu nas relações privadas.

De acordo com o Rodrigo da Cunha Pereira, ${ }^{25}$

A dicotomia entre público e privado continua sendo uma das grandes questões para o Direito de Família. Até que ponto o Direito, e consequentemente o Estado Democrático de Direito, deve interferir na vida privada e proibir ou ilegitimar determinados tipos de família? A meu ver, o Estado só deveria intervir para garantir a autonomia privada. E isto não seria nenhum problema, se as novas formatações familiares não fossem perpassadas por conteúdos morais e religiosos e se essas convicções se limitassem às próprias religiões e não impusessem essa moral particular, ou de um determinado segmento, à toda população. Se ficasse cada um no seu quadrado poderíamos, de fato e de direito, termos um

${ }_{25}$ PEREIRA, Rodrigo da Cunha. Limites do direito devem garantir autonomia privada a moralismo. Disponível em: < <ttp://www.rodrigodacunha.adv.br/limites-direito-devem-garantir-autonomia-privada-semceder-moralismo-2/> . Acesso em: 03 jul. de 2018 
verdadeiro Estado laico, e a vida privada, autonomia e liberdade das pessoas estariam preservadas. Devemos respeitar todas as religiões, e levá-las a sério como um sistema simbólico que veicula verdades profundas da existência humana, apesar de todo mal que ainda se pratica em nome dela. Religião é bom para nos confortar diante de nossa finitude e desamparo estrutural. Ela passa a ser maléfica quando é deturpada para utilização de poderes políticos e econômicos, como tem acontecido no Brasil.

Dessa maneira, o princípio da liberdade corresponde ao livre poder de escolha e da autonomia da pessoa, de constituir, realizar ou extinguir a entidade familiar, sem que haja imposições arbitrárias de instituições religiosas, de parentes, da sociedade ou do legislador.

Caso seja um núcleo fundado em um casal, será constituído na livre decisão de ambos, e não unilateralmente; se for uma família constituída por uma mãe solteira e um filho, o mesmo tem autonomia após a maioridade, de recusar o reconhecimento voluntário da paternidade feito pelo seu pai biológico, podendo optar para que no registro de nascimento conste somente o nome da mãe. ${ }^{26}$

Esses são exemplos, dentre muitos, do exercício do princípio da liberdade nas entidades familiares, pois não faz sentindo o Estado, ou qualquer outra instituição, ter interesse em regular relações que se estabeleceram de forma tão particular e íntima. Diz respeito não apenas à criação, manutenção ou extinção dos arranjos familiares, mas também a sua permanente constituição e reinvenção.

Já o princípio do pluralismo das entidades familiares, por sua especificidade, encontra fundamento essencialmente no princípio da liberdade, ambos se completam pois interagem entre si quando determinam o reconhecimento e a efetiva proteção do Estado, das múltiplas possibilidades de arranjos familiares, sem qualquer represamento, garantindo a plena liberdade de conceber uma família fundada em valores humanos, fraternos e plurais.

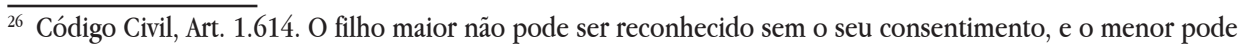
impugnar o reconhecimento, nos quatro anos que se seguirem à maioridade, ou à emancipação. 


\section{DA NÃO INTERVENÇÃO DO ESTADO NAS RELAÇÕES PARTICULARES}

A família certamente é o meio mais delicado e polêmico da intervenção estatal, por se tratar de um ambiente íntimo e extremamente particular, onde as relações, em regra, são informais e peculiares.

Nessa perspectiva, busca-se compor um cotejo analítico entre a autonomia privada e a intervenção estatal, ilustrando os significados tanto de um "Estado ausente" como de um "Estado presente" que possibilitam a proteção da pessoa humana.

Não seria um exagero afirmar que antigamente a tradicional família brasileira era limitada em representar uma aquarela de tonalidades e cores morais e sociais, em lugar de ser uma tela, como agora é, policrômica para o desenho do sentimento e do afeto. ${ }^{27}$ Essa nova estrutura abriu espaço para o reconhecimento que outros inúmeros modelos, resultado de uma série de modificações sociais, especialmente ocorridas aos anos que sucederam a Constituição Federal de 1988.

Foi nessa medida que o constitucionalismo buscou, por meio dos princípios fundamentais, o real significado da entidade familiar, pelo qual se estabelece como uma organização reunida por desejos e afetos múltiplos em comunhão de vida. O princípio jurídico da afetividade cumpre papel fundamental nessa função de reestruturação da família, pois é o propulsor que insere a pessoa humana à frente nas relações familiares trazendo o afeto como o pilar que sustenta a entidade.

Dessa maneira, alteraram-se posteriormente outras leis, como foi o caso do Código Civil de 2002. Isso fez com que houvesse uma repersonalização do direito privado, que deixou para trás a ideia de que o patrimônio vale mais que a vida e as relações humanas.

Partindo, então, do preceito de que o ser humano é sujeito não só de necessidades materiais, mas também de necessidades imateriais a tutela, por conseguinte, passa a ser direcionada sobretudo no valor da pessoa e por essa razão excluir as relações jurídicas pautadas em afeto, só pelo motivo dessas não se moldarem à tradição familiar de tempos atrás, implica em negar mais do que um modelo, importa verdadeiramente, em omitir a própria condição existencial da pessoa que vivência e busca a felicidade em si próprio e no afeto para com o outrem.

Acatar as múltiplas possibilidades do amor é respeitar as escolhas pessoais

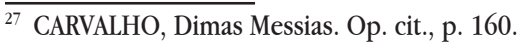


de cada um, visto que isso significa mais do que atribuir liberdade. É precioso destacar que o Estado deve agir para garantir os direitos que humanizam cada vez mais o sentido das relações humanas, e não que seja veículo de intolerância e arbitrariedade.

Sob a matriz desses princípios, não cabe ao Estado ditar a possibilidade ou, até mesmo, a impossibilidade de constituição de famílias simultâneas, uma vez que a estruturação dessas famílias não se deve inferir do ordenamento jurídico, mas, sim, das situações de fato que são construídas sobre o afeto. Aliás tais relações podem se configurar tanto na perspectiva entre pais e filhos, como em relações conjugais.

Nesse sentido é que se faz indispensável a abstenção estatal para beneficiar o livre desenvolvimento da personalidade e da pluralidade familiar, pois propor a intervenção estatal no âmbito familiar, espaço esse, que deve ser desenvolvido a livre personalidade humana é cercear os direitos personalíssimos das pessoas que pretendem se realizar, em coexistência naquele espaço familiar.

No entanto, ao mesmo tempo em que é necessária a ausência do Estado para permitir o livre desenvolvimento das pessoas constituírem suas relações entre si, também é necessária a presença da ação estatal quando há situações potencialmente lesiva ao desenvolvimento da personalidade de uma pessoa.

O reconhecimento dessa vulnerabilidade, desse modo, permite que o Estado realize intervenções no seio familiar que servem para proteger os direitos que são desprotegidos, naturalmente. Emerge então a necessidade do "Estado presente", que interfere no particular para a sua prevenção e o pleno desenvolvimento da personalidade humana.

\section{DO RECONHECIMENTO DA UNIÃO POLIAFETIVA}

Denota-se que a sociedade brasileira, apesar da abundância cultural poligâmico histórico que possui na sua bagagem, não optou pela forma poligâmica de família, sendo que a monogamia foi um o valor socialmente consolidado e historicamente construído. ${ }^{28}$

Após a promulgação da atual Constituição Federal, o direito da família passou por incontestáveis mudanças e exaltou a importância de valores que antes

${ }^{28}$ SIMÃO, José Fernando. Poligamia, Casamento Homoafetivo Escritura pública e dano social: Uma reflexão necessária. Disponível em: < https://bit.ly/2u1PhdC > Acesso em: 03 jul. de 2018. 
não eram cobrados, tais como a boa-fé entre os parceiros, a efetividade, a estabilidade e a ostensibilidade. Esses são os elementos que fazem da união familiar um vínculo válido e efetivo.

No que tange à poliafetividade, é importante ressaltar que para esse tipo de conduta, não existe de fato uma punição efetiva. A bigamia é um crime, mas como se fosse uma letra morta, porque ninguém aplica essa figura penal nos dias atuais. ${ }^{29}$ Ademais, mesmo que fosse considerado o crime de bigamia um obstáculo para o reconhecimento das uniões poliafetivas, não seria contemplado como verdade tal afirmativa, uma vez que os envolvidos não se relacionam entre si de forma distinta e, sim, concomitantemente. A poliafetividade é um conceito de amor múltiplo e, por isso, todos os que estão se relacionando participam da união de forma simultânea e consciente.

Portanto, essas relações são pautadas na verdade recíproca entre os comprometidos, e não há subalternidade de nenhum lado, por isso o relacionamento também é válido, pois expõe a livre vontade dos envolvidos.

Não cabe ao Estado e, tão pouco, aos operadores do direito ditarem os limites do amor entre as pessoas. Na verdade, cumpre ao Estado e à sociedade a proteção, o respeito e a promoção dos direitos que esse novo núcleo familiar tanto anseia, para que os direitos, individuais e sociais sejam garantidos com eficácia plena.

\section{CONCLUSÃO}

O direito de família encontra-se particularmente relacionado à evolução histórica da sociedade e, consequentemente às entidades familiares. Os arranjos afetivos poliamorosos estão cada vez mais se tornando uma realidade social.

São relacionamentos baseados no afeto, na vontade livre das partes e neste momento sofrem com a omissão do Estado, que se nega em reconhecer essas uniões como entidade familiar e, por essa razão, tais famílias não recebem nenhuma tutela específica do Estado que possa proteger seus direitos de família.

Destaca-se que antes da decisão do Conselho Nacional de Justiça, que proibiu os cartórios de registrarem as uniões poliafetivas, era possível efetivar o registro das pessoas que pretendiam formalizar essa união, visto que de fato não

${ }^{29}$ POLIAMORISMO: relacionamento a três é oficalizado por juiz. O Estado: Direito e Justiça, 2014. Disponível em: <https://issuu.com/oestadoce/docs/02_d_j>. Acesso em: 31 jul. 2018. 
existe qualquer lei que proíba esses relacionamentos de existirem.

Portanto, a tutela jurídica dessas uniões encontra-se até o momento desamparadas, simbolizando uma real omissão do Estado.

Nesse sentindo, entende-se que se a família for pensada em um viés plural aberto, e entendida como espaço de uma autoconstituição coexistencial, não cabe ao Estado e nem à comunidade definir como essa autoconstituição deve ser desenvolvida, e por quais pilares será constituída.

Defende-se, então, que o Estado deve reconhecer as vontades íntimas dos particulares, uma vez que as leis por certo modo decreta estabilidade legislativa que é relevante para a segurança jurídica, todavia, pode ser também fonte de exclusão e juízos pré-concebidos que partem de uma tradição retrógada e preconceituosa.

\section{REFERÊNCIAS}

AZEVEDO, Camyla Galeão de; AZEVEDO, Thiago Augusto Galeão de. A constitucionalidade do poliamor: possível aplicabilidade do direito sucessório aos companheiros das entidades poliafetivas. Revista Brasileira de Direito Civil em Perspectiva, Salvador, v. 4, n. 1, p. 166-189, jan./jun. 2018. Disponível em: <indexlaw.org/index.php/direitocivil/article/view/4292/pdf> . Acesso em: 26 nov. 2018.

BRASIL, Supremo Tribunal Federal. Ação Direita de Inconstitucionalidade 4277. Rel. Min. Ayres Brito, 2011.

BUCHE, Giancarlos. Famílias Simultâneas: O Poliamor no Sistema Jurídico Brasileiro. Revista Eletrônica OAB Joinville, Joinville, v. 2, n. 2, abr.jun. 2011. Disponível em: < http://revista.oabjoinville.org.br/artigo/78/familias-simultaneas-opoliamorno-sistema-juridico-brasileiro > . Acesso em: 26 nov. 2018.

CARVALHO, Dimas Messias. Direito das famílias. 5. ed. São Paulo: Saraiva, 2017.

COSTA, Tatiane; BELMINO, Marcus Cézar. Poliamor: da institucionalização da monogamia à revolução sexual de Paul Goodman. Revista IGT na Rede, v. 12, n. 23, p. 411-429, 2015.

DIAS, Maria Berenice. Manual de Direito das Famílias. 3. ed. São Paulo: Revistas 
dos Tribunais, 2006.

DIAS, Maria Berenice. Manual de Direito das Famílias. 9. ed. São Paulo: Revistas dos Tribunais, 2013.

DIAS, Maria Berenice. Poliafetividade, alguém dúvida que existe? Disponível em: < http://www.mariaberenice.com.br/manager/arq/(cod2_552)poliafetividade. pdf $>$. Acesso em: 26 jul. 2018.

FELL, Elizângela Treméa; SANCHES, Jeniffer Balen. Possibilidade de reconhecimento da união poliafetiva como entidade familiar e suas respectivas implicações perante o ordenamento jurídico pátrio. Revista de Direito de Família e Sucessão, v. 2, n. 2, p. 1 -19, 2016. Disponível em: <indexlaw.org/index.php/ direitofamilia/article/view/1272/pdf>. Acesso em: 26 nov. 2018.

FRANÇA, Matheus Gonçalves. Além de dois existem mais: estudo antropológico sobre poliamor em Brasília/DF. 2016. 136f. Dissertação (Mestrado em Antropologia Social) - Instituto de Ciências Sociais, Universidade de Brasília, Brasília, 2016.

GOEDERT, Gabriela. Uniões poliafetivas: o reconhecimento jurídico como entidade familiar. 2016. 100 f. Monografia (Graduação em Direito) - Centro de Ciências Jurídicas, Universidade Federal de Santa Catarina, Florianópolis, 2016.

LINS, Regina Navarro. A cama na varanda: arejando nossas ideias a respeito do amor e sexo: novas tendências. Rio de Janeiro: BestSeller, 2007.

LINS, Regina Navarro. O Livro do Amor. Rio de Janeiro: BestSeller, 2012, v 1.

LÔBO, Paulo. Direito Civil Famílias. 4. ed. São Paulo: Saraiva, 2011.

MATTEI, Márcia Zomer Rossi. Poliafetividade: a quebra da monogamia no Brasil. Revista Constituição e Justiça: Estudos e Reflexões, v. 1, n. 1, p. 116-142, 2017. Disponível: < periodicos.unibave.net/index.php/constituicaoejustica/article/ view/132/116>. Acesso em: 26 nov. 2018.

MOITINHO, Rodrigo. et al. Poliamorismo e o reconhecimento das relações poliafetivas como núcleo familiar. 2018. Disponível em: < https://jus.com.br/ artigos/64819/poliamorismo-e-o-reconhecimento-das-relacoes-poliafetivas-comonucleo-familiar > . Acesso em: 02 jul. 2018. 
NUNES, Danilo Henrique; LEHFELD, Lucas de Souza. As relações poliafetivas, omissão regulatória e seus reflexos jurídicos nas questões de direito previdenciário. Revista da Faculdade Mineira de Direito, v. 21, n. 41, p. 225-244, 2018. Disponível em: <200.229.32.55/index.php/Direito/article/view/18199/13893>. Acesso em: 26 nov. 2018.

OLIVIEIRA, NHD. Recomeçar: família, filhos e desafios. São Paulo: UNESP Cultura Acadêmica, 2009. Disponível em: < https:/bit.ly/2nwIKDT > Acesso em: 02 jul. 2018.

PEREIRA, Rodrigo da Cunha. Limites do direito devem garantir autonomia privada a moralismo. Disponível em: < http://www.rodrigodacunha.adv.br/ limites-direito-devem-garantir-autonomia-privada-sem-ceder-moralismo-2/> . Acesso em: 03 jul. 2018.

PEREZ, Tatiana Spalding; PALMA, Yáskara Arrial. Amar amores: o poliamor na contemporaneidade. Revista Psicol. Soc., Belo Horizonte, v. 30, 2018. Disponível em: < http://www.scielo.br/scielo.php?script = sci_arttext\&pid=S0102$71822018000100208 \& \operatorname{lng}=$ en\&nrm $=$ iso $>$. Acesso em: 26 nov. 2018.

PIVA, Juliana Dal. Rio registra primeira união estável entre três mulheres. Jornal Folha de São Paulo, 2015. Disponível em: < https://brasil.estadao.com.br/noticias/ rio-de-janeiro,rio-registra-primeira-uniao-estavel-entre-3-mulheres, 1781538>. Acesso em: 27 jul. 2018.

PILÃO, Antonio Cerdeira. Entre a liberdade e a igualdade: princípios e impasses da ideologia poliamorista. Cadernos Pagu, n. 44, p. 391-422, jan./jun. 2015.

POLIAMORISMO: relacionamento a três é oficalizado por juiz. O Estado: Direito e Justiça, 2014. Disponível em: < https:/issuu.com/oestadoce/docs/02_d_j > . Acesso em: 31 jul. 2018.

RABELO, Claudia Mara de Almeida; POLI, Leonardo Macedo. O reconhecimento da família poliafetiva no Brasil: uma análise à luz dos princípios da dignidade humana, autonomia privada, pluralismo familiar e isonomia. Revista Duc In Altum Cadernos de Direito, v. 7, n. 13, p. 54-99, set./dez. 2015.

ROSA, Angélica Ferreira; DE OLIVEIRA, José Sebastião. As relações poliafetivas 
são permitidas no direito de família brasileiro? Revista Argumenta, Jacarezinho, n. 26, p. 197-218, jan./jun. 2017. Disponível em: < https:// search.proquest.com/openview/131b2dafa5c323ec23e68eee278bed10/1?pqorigsite $=$ gscholar $\& \mathrm{cbl}=2031966>$. Acesso em: 26 nov. 2018.

ROSA, Conrado Paulino da. iFamily: um novo conceito de família? São Paulo: Saraiva, 2013.

ROTONDONO, Ricardo Oliveira. Fundamentos pela abertura jurídica ao poliamor: liberdade, democracia e pluralismo. REJUR - Revista Jurídica da UFERSA, Mossoró, v. 2, n. 3, p. 139-156, jan./jun. 2018. Disponível em: < https://periodicos. ufersa.edu.br/index.php/rejur/article/view/7257/pdf > . Acesso em: 26 nov. 2018.

ROUDINESCO, Elisabeth. A família em desordem. Rio de Janeiro: Zahar, 2003.

SILVA, Alexandre Barbosa da. Escrituras para uniões poliafetivas : algumas impressões sobre mais essa novidade no direito das famílias. Revista Direito Unifacs: debate virtual, n. 214, p. 1-38, abr. 2018.

TEIXEIRA, Matheus. Relações a três. Disponível em: < https://www.jota.info/eticajota\# aceitacao-dos-termos-e-condicoes-de-uso > . Acesso em: 27 jul. 2018.

UNIÃO Estável entre três pessoas é oficializada no cartório de Tupã, SP. G1/Globo comunicações, 2012. Disponível em < http://g1.globo.com/sp/bauru-marilia/ noticia/2012/08/uniao-estavel-entre-tres-pessoas-e-oficializada-em-cartorio-de-tupasp.html >. Acesso em: 27 jul. 2018.

VITERBO, Luís Miguel; POLY, Lara; CARDOSO, Daniel. Poliamor? O que é? Issuu, 2010. Disponível em: < https://issuu.com/poliamor/docs/flyers_polyportugal > Acesso em: 31 jul. 2018.

ZANON, Susana Raquel Bisognin. Poliamor: o não-todo e a inconsistência da lei. Revista Científica Ciência em Curso, Palhoça, v. 3, n. 2, p. 167-180, jul./dez. 2014. 